\title{
Análise espaço-temporal da vegetação no semiárido do Nordeste brasileiro utilizando parâmetros biofísicos
}

Spatio-temporal analysis of vegetation in the semiarid of brazilian northeast using biophysical parameters

\author{
SILVA, Geovane de Andrade. Graduando/ Engenharia de Pesca \\ Universidade Federal Rural de Pernambuco-UFRPE, Unidade Acadêmica de Serra Talhada-UAST, Av. Gregório \\ Ferraz Nogueira, S/N - José Tomé de Souza Ramos, Serra Talhada/PE, Brasil. CEP: 56909-535. Fone: (87) 3029- \\ 3056. E-mail: geovaneandradep@gmail.com
}

FARIAS, Carolyne Wanessa Lins de Andrade. Doutorado/ Engenharia Agrícola

Universidade Federal da Paraíba-UFPB, Campus I - Lot. Cidade Universitária, João Pessoa/PB, Brasil. CEP: 58051-900. Fone: (83) 3216-7750. E-mail: carolynelins.ufpb@gmail.com

\section{RESUMO}

O objetivo do trabalho consiste em realizar uma análise espaço-temporal da vegetação em um município do semiárido do Nordeste brasileiro por meio de índices biofísicos, utilizando técnicas de geoprocessamento e sensoriamento remoto. $O$ estudo foi realizado na cidade de Parnamirim - PE. Os índices biofísicos utilizados foram o Índice de Vegetação por Diferença Normalizada (NDVI) e o Índice de Umidade por Diferença Normalizada (NDWI), gerados a partir da análise de imagens orbitais do satélite Landsat 8, referentes aos anos de 2015 e 2019, para o período chuvoso, e 2016 e 2020, considerando o período seco da região. O período chuvoso de 2019 apresentou maior exuberância da vegetação e maior presença de água no ambiente, quando comparado ao ano de 2015. No período seco, verificou-se que 2020 foi caracterizado por maiores densidades de vegetação e presença de água em relação ao ano de 2016. Áreas com menor exuberância de vegetação, podem ser adotadas como prioritárias para a adoção de ações de recuperação. As informações geradas por este estudo são relevantes para subsidiar ações de recuperação de áreas degradadas, criação de políticas públicas, planejamento e gestão ambiental.

Palavras-Chave: Sensoriamento remoto, NDVI, NDWI.

\begin{abstract}
The objective of the work is to perform a spatio-temporal analysis of vegetation in a municipality in the semiarid region of Brazilian Northeast using biophysical indices and techniques of geoprocessing and remote sensing. The study was performed in the city of Parnamirim - PE. The biophysical indices used were the Normalized Difference Vegetation Index (NDVI) and the Normalized Difference Water Index (NDWI), generated from the analysis oorbital images from the Landsat 8 satellite, referring to the years 2015 and 2019, for the rainy season, and 2016 and 2020, considering the dry season in the region. It is concluded that in the rainy period of 2019, there is a greater exuberance of vegetation and a greater presence of water in the environment, when compared to the 2015 year. In the dry period, it was found that 2020 was characterized by higher density of vegetation and the presence of water compared to the year 2016. Areas with less exuberance of vegetation can be adopted as priorities for the adoption of recovery actions. The information generated by this study is relevant to support actions for the recovery of degraded areas, creation of public policies, planning and environmental management.
\end{abstract}

Keywords: Remote sensing, NDVI, NDWI. 
SILVA, Geovane de Andrade; FARIAS, Carolyne Wanessa Lins de Andrade (2021)

Análise espaço-temporal da vegetação no semiárido do Nordeste brasileiro utilizando parâmetros biofísicos

\section{Introdução}

No semiárido brasileiro, o regime pluviométrico é marcado por extrema irregularidade no tempo e no espaço. Neste cenário, a escassez de água estabelece um grande impedimento ao desenvolvimento socioeconômico da região. Esta condição provoca impactos na distribuição espaçotemporal da cobertura vegetal da região, e consequentemente, gera modificações no ciclo hidrológico (Gonzaga et al., 2011).

Segundo Freire et al. (2010), o desafio atual consiste em propor instrumentos tecnológicos que possibilitem análises alternativas e adequadas para a melhoria da qualidade de vida e bemestar socioeconômico da população de uma região. Portanto, a relevância de monitoramento em diferentes escalas espacial e temporal, é essencial na perspectiva de tomada de decisões.

Nos últimos anos, técnicas de geoprocessamento e sensoriamento remoto vêm cada vez mais mostrando sua importância como ferramenta para auxiliar caracterizações litológicas, topográficas, hidrológicas e sedimentológicas (Rebouças et al., 2019). Segundo Azevedo e Mangabeira (2001), uma série de funções anteriormente atendidas pela aerofotogrametria, podem ser aplicadas pelo sensoriamento remoto adicionando uma série de vantagens, a saber: baixo custo por área específica; aspectos diacrônico (alta frequência de repetitividade da tomada de imagens) e sincrônico da captação das imagens; aspecto multiespectral das imagens; caráter digital dos dados adquiridos; e, facilidade de integração com bases de dados geocodificados, cartográficos ou numéricos, através de Sistemas de Informação Geográfica (SIGs).

A utilização de softwares livres gratuitos baseados em SIGs, como o Quantum GIS (QGIS), vem crescendo ao longo dos anos, sendo aplicados em pesquisas voltadas a análise espacial do território. De acordo com Ito et al. (2017), softwares livres como o QGIS possibilitam melhorar as competências na formação acadêmica e possibilitam grande economia financeira para a instituição e/ou propicia o redirecionamento de investimento. Os softwares privados e pagos, denominados softwares proprietários, demandam dependência tecnológica e às vezes custo alto, além das restrições de uso, pois os programas de código fechado são limitados e seus algoritmos não estão disponíveis.

Dentre os diversos índices biofísicos, pode-se citar o Índice de Vegetação por Diferença Normalizada (NDVI), proposto por Rouse et al. (1973), com ampla aplicação na análise espacial e no desenvolvimento da cobertura vegetal, e o Índice de Umidade por Diferença Normalizada (NDWI), elaborado por Gao et al. (1996), relacionado à avaliação da escassez hídrica. Estes índices auxiliam no entendimento da dinâmica da vegetação, destacando-se os estudos desenvolvidos por Bilar et al. (2018), que analisaram a cobertura vegetal da área monitorada do Parque Estadual da Mata da Pimenteira (PEMP), utilizando os índices de vegetação NDVI e NDWI, a fim de auxiliar no monitoramento ambiental e tomada de decisões relacionadas à gestão dessa unidade de conservação; e Silva Júnior et al. (2018), que verificaram a umidade em períodos chuvosos utilizando o NDWI e o NDVI, no Munícipio de Água Branca - AL, a qual apresenta clima semiárido.

Diante do exposto, o objetivo do trabalho consiste em realizar uma análise espaço-temporal da vegetação em um município do semiárido do Nordeste brasileiro por meio dos índices biofísicos 
SILVA, Geovane de Andrade; FARIAS, Carolyne Wanessa Lins de Andrade (2021).

Análise espaço-temporal da vegetação no semiárido do Nordeste brasileiro utilizando parâmetros biofísicos

NDVI e NDWI.

\section{Material e Métodos}

\section{1 Área de estudo}

O estudo foi conduzido na cidade de Parnamirim, Pernambuco, com extensão territorial de aproximadamente $2.621 \mathrm{~km}^{2}$, situada a $570 \mathrm{~km}$ de distância da capital do estado, e inserida na Mesorregião do sertão pernambucano, com coordenadas geográficas de $08^{\circ} 05^{\prime} 26^{\prime \prime}$ de latitude sul e $39^{\circ} 34^{\prime} 42^{\prime \prime}$ de longitude oeste, e 392 m acima do nível do mar (Figura 1).

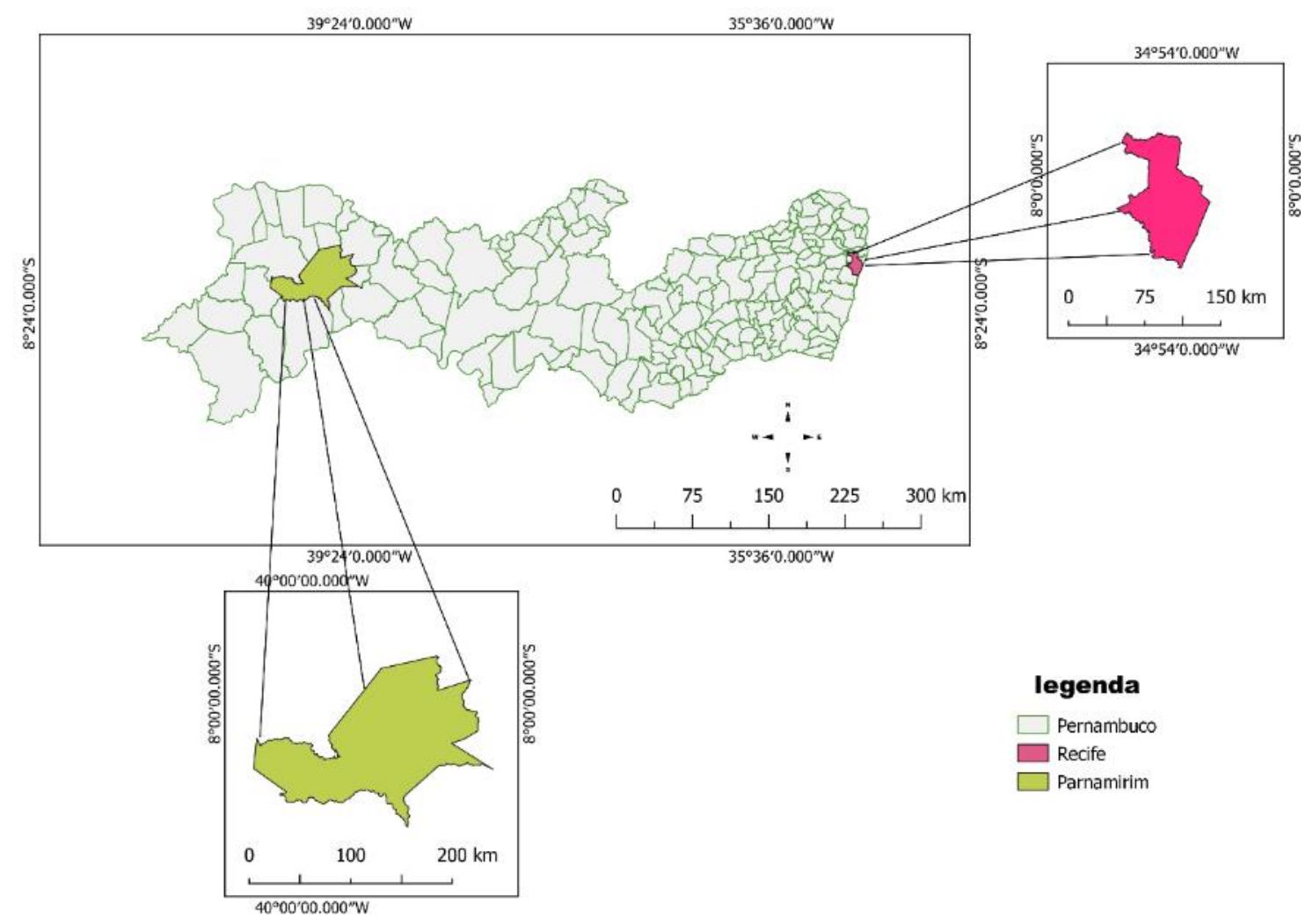

Figura 1: Mapa de localização geográfica do município de Parnamirim, no sertão pernambucano, situado a $570 \mathrm{~km}$ da capital Recife (Fonte: Elaborado pelos autores).

\subsection{Procedimentos para coleta e análise dos dados}

Neste estudo, foram utilizadas quatro imagens orbitais captadas pelo sensor Operational Land Imager (OLI) do satélite Landsat 8, com resolução espacial de 30×30 metros e resolução temporal de 16 dias, com órbita/ponto 217/066, referentes às datas de passagem 14/12/2015 e 25/12/2019 para o período chuvoso, e 29/10/2016 e 08/10/2020 para o período seco, obtidas gratuitamente através do site: http://www.dgi.inpe.br/catalogo/. Foram escolhidas imagens com um baixo percentual de nuvens e que representassem períodos secos e chuvosos em diferentes anos, considerando a variação temporal.

Para a identificação das características pluviométricas temporais na área estudada, foram utilizados dados do clima da cidade obtida em plataforma "weathers park", disponível em: 
SILVA, Geovane de Andrade; FARIAS, Carolyne Wanessa Lins de Andrade (2021)

Análise espaço-temporal da vegetação no semiárido do Nordeste brasileiro utilizando parâmetros biofísicos

https://pt.weatherspark.com/y/31013/Clima-característico-em-Parnamirim-Brasil-durante-o-ano. Foram selecionados os dados diários de precipitação dos anos de imagens OLI utilizadas nesta pesquisa, nos respectivos períodos seco e chuvoso, em anos distintos. A Figura 2 apresenta a precipitação média mensal na estação de Parnamirim - PE. O período chuvoso dura aproximadamente sete meses, entre novembro e maio, com precipitação máxima mensal de $112 \mathrm{~mm}$.

0 período seco dura aproximadamente três meses, entre setembro e dezembro, com temperatura máxima média de $35^{\circ} \mathrm{C}$.

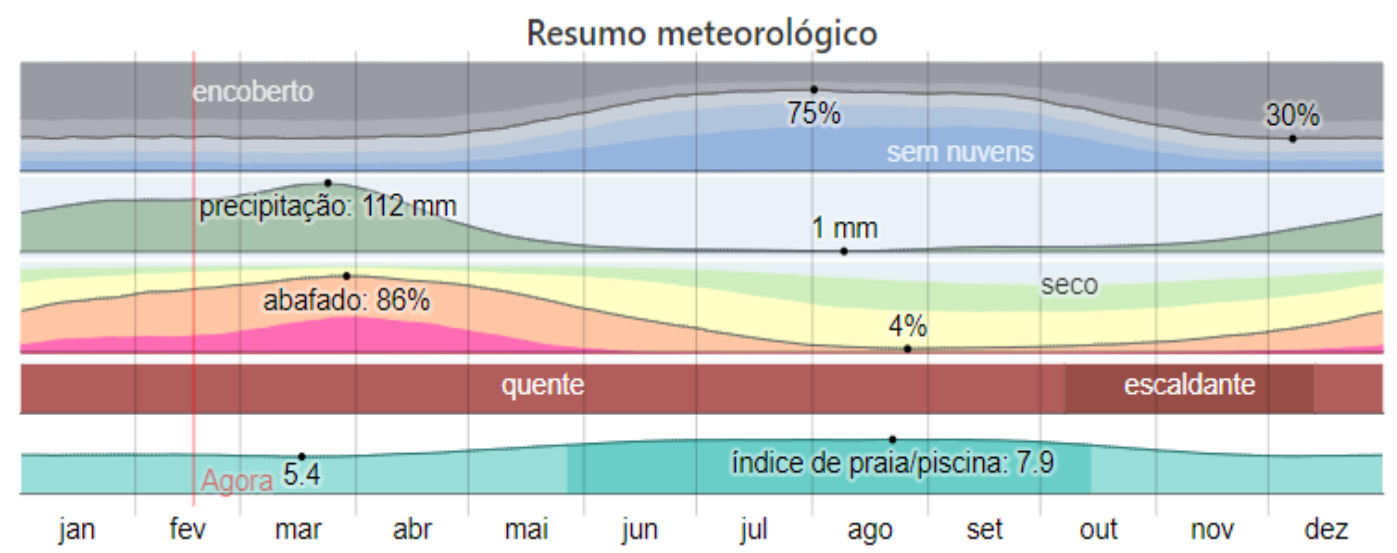

Figura 2. Precipitação média mensal do município de Parnamirim - PE. Fonte: weatherspark.com

Para a visualização e realização das operações matemáticas utilizou-se o software livre e gratuito Quantum GIS versão 3.10.14, e foram utilizadas as bandas reflectivas de 4 a 6 , além do metadados das imagens.

\section{3 Índices de vegetação}

Para avaliar a condição da vegetação foram calculados os índices: NDVI (Índice de Vegetação por Diferença Normalizada) e NDWI (Índice de Umidade por Diferença Normalizada). Inicialmente, foi realizada a conversão dos níveis de cinza para radiância e refletância, utilizando coeficientes radiométricos de calibração encontrados nos metadados da imagem, conforme Equação 1.

$$
\rho \lambda^{\prime}=\frac{\mu \rho \times Q \operatorname{caX} A \rho}{\sin (\theta S e)}
$$

Onde: $\rho \lambda$ ' é refletância; $\mu \rho$ é reflectância_multi_banda_x; A $\rho$ é reflectancia_add_banda_x; $\sin$ in $(\theta S e)$ é a elevação do sol; e Qca é o número digital da imagem.

O NDVI, proposto por Rouse et al. (1973), foi utilizado para identificar a distribuição e o desenvolvimento da vegetação, onde os valores variam entre -1 e +1 . Os valores negativos correspondem aos corpos hídricos e os positivos informam sobre a exuberância da vegetação verde na superfície e elevada quantidade de biomassa, sendo determinado pela Equação 2. 
SILVA, Geovane de Andrade; FARIAS, Carolyne Wanessa Lins de Andrade (2021).

Análise espaço-temporal da vegetação no semiárido do Nordeste brasileiro utilizando parâmetros biofísicos

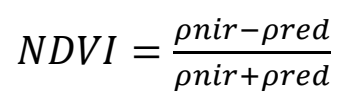

Onde: pnir é o fluxo radiante refletido no infravermelho próximo, representado pela banda 5 do sensor $\mathrm{OLI}$, do Landsat 8 , e pnred é o fluxo radiante refletido no vermelho da região visível, representado pela banda 4 , do sensor OLI, do satélite Landsat 8.

O NDWI foi calculado para monitorar o estresse hídrico, comum no semiárido, e por ter menor sensibilidade a efeitos atmosféricos (Oliveira et al., 2010). Quanto maior a presença de água no ambiente, maior será o valor do NDWI. Sua equação foi proposta por Gao et al. (1996), Equação 3.

$$
N D W I=\frac{\rho n i r-\rho r e d}{\rho n i r+\rho r e d}
$$

Onde: pmidir é o fluxo radiante refletido no infravermelho médio, representado pela banda 6 do satélite Landsat 8.

\section{Resultados e Discussão}

As figuras 3 a 6 apresentam os valores de NDVI e NDWI, para os períodos chuvosos e secos, em anos diferentes, no município de Parnamirim - PE. Os períodos e anos avaliados apresentaram valores de NDVI e NDWI bastante distintos.

Os valores do NDVI no período chuvoso do ano de 2015 estiveram, predominantemente, no intervalo entre 0,245 e 0,509, sendo representados pelas cores marrom e amarelo (Figura 3A), indicando uma exuberância da vegetação, com valores de NDVI predominantemente positivos. No ano de 2019, os valores de NDVI ficaram entre 0,245 a 1,000, sendo representados pelas cores marrom, amarelo e vermelho. As áreas que possuem cobertura vegetal mais densa estão representadas por uma zona de cores amarelo e vermelho (de 0,358 a 1,00) e correspondem à uma fração da cena. Este intervalo indica menor frequência de solo exposto, quando comparado ao ano de 2015, com maior densidade da vegetação presente no período chuvoso do ano de 2019, principalmente na porção Norte do município (Figura 3B).

A menor quantidade de cobertura vegetal no ano de 2015 está associada aos menores índices pluviométricos neste ano. De acordo com Lima e Carvalho (2018), quanto mais próximo de 1 , maior é a quantidade de vegetação presente na área de estudo. Brito et al. (2017), analisando o comportamento da vegetação em áreas de Caatinga preservada no município de Petrolina - PE, relataram que a predominância de valores entre 0 e 0,2 está geralmente associada a presença de solo exposto. A combinação das alterações do clima na forma de ausência ou escassez de chuva, acompanhada de altas temperaturas e altas taxas de evaporação e com competição por recursos hídricos, pode levar a uma crise potencialmente catastrófica, sendo os mais vulneráveis a população mais carente, como os agricultores do semiárido do Nordeste, visto que esta região já enfrenta um problema crônico de falta de água (Marengo et al., 2011). 
SILVA, Geovane de Andrade; FARIAS, Carolyne Wanessa Lins de Andrade (2021) Análise espaço-temporal da vegetação no semiárido do Nordeste brasileiro utilizando parâmetros biofísicos
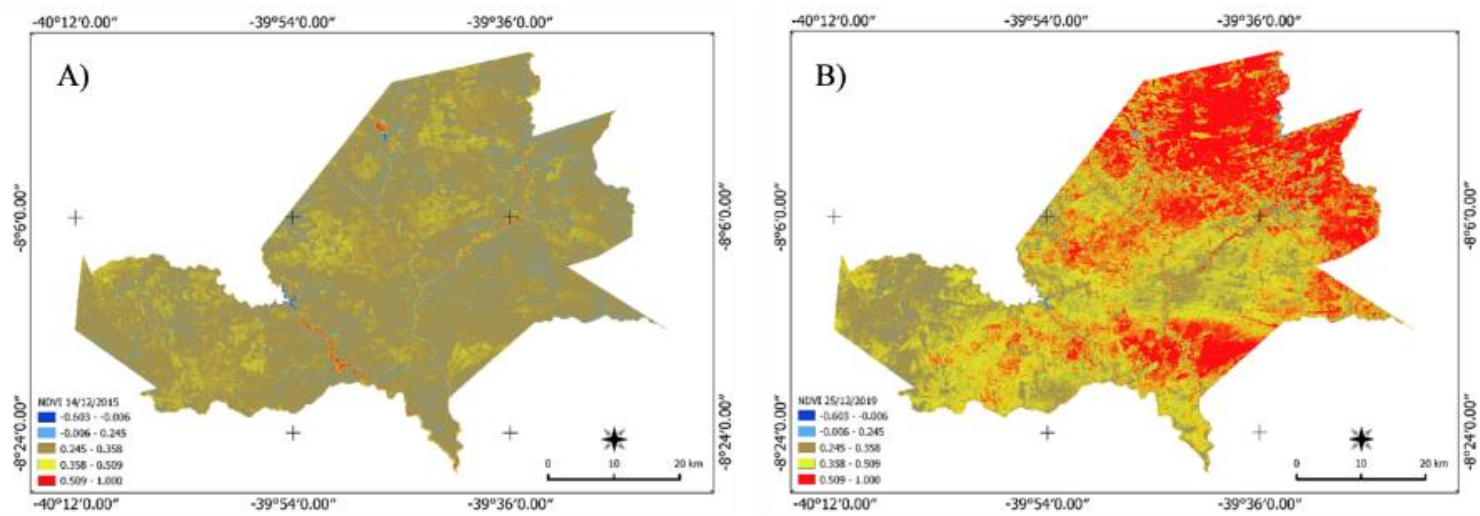

Figura 3: Comparativo dos Índices de Vegetação por Diferença Normalizada (NDVI) do município de Parnamirim - PE para as datas: 14/12/2015 (A) e 25/12/2019 (B), períodos chuvosos (Fonte: Elaborado pelos autores).

O NDWI no período chuvoso de 2015 apresentou valores predominantes entre -0,373 e 0,123, indicando elevados índices de solo úmido (Figura 4A). No ano de 2019, o NDWI esteve predominantemente no intervalo de $-0,199$ a 0,645, indicando maior presença de água no solo, quando comparado ao ano de 2015 (Figura 4B). Silva Júnior et al. (2018), realizando análise do NDVI e NDWI no município de Água Branca - AL, encontraram valores de NDWI variando entre -0,81 e $-0,49$ no mês de dezembro de 2017 , apresentando pixels com características de baixa umidade e áreas com pouca presença de corpos hídricos. Neste período, o índice pluviométrico da região foi baixo, chovendo apenas $35 \mathrm{~mm}$, o que acarretou na mudança da umidade do solo. Segundo Santos et al. (2019), o conhecimento da variabilidade espaço-temporal da precipitação torna-se importante no contexto da gestão do risco de seca, seja para subsidiar a tomada de decisões em relação às tendências climáticas, como para o monitoramento de eventos extremos de precipitação em curto e médio prazo.
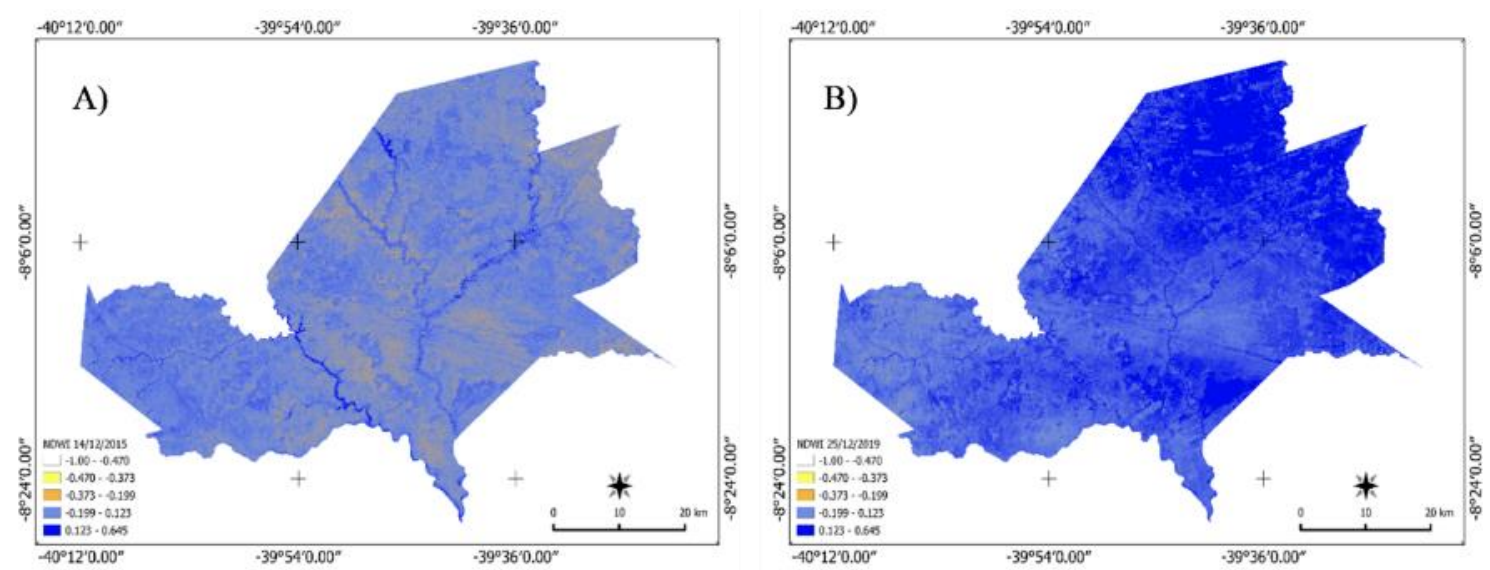

Figura 4. Comparativo dos Índices de Umidade por Diferença Normalizada (NDWI) do município de Parnamirim - PE para as datas: 14/12/2015 (A) e 25/12/2019 (B), períodos chuvosos (Fonte: Elaborado pelos autores).

Os valores do NDVI no período seco do ano de 2016 estiveram, predominantemente, no intervalo entre 0,245 e 0,509, representados pelas cores marrom e amarelo (Figura 5A), com 
SILVA, Geovane de Andrade; FARIAS, Carolyne Wanessa Lins de Andrade (2021).

Análise espaço-temporal da vegetação no semiárido do Nordeste brasileiro utilizando parâmetros biofísicos

maiores áreas com NDVI entre 0,358 e 0,509, quando comparado ao período chuvoso de 2015 . No ano de 2020, os valores de NDVI também ficaram entre 0,245 e 0,509, representados pelas cores marrom e amarelo. Entretanto, este ano apresentou maior densidade de NDVI com valores entre 0,358-0,509 (amarelo) quando comparado ao período seco de 2016, indicando que o ano de 2020 apresentou maior exuberância da vegetação, distribuída por todo o município (Figura 5B). A presença de baixa vegetação do bioma Caatinga no período seco, que ocorre em meados de setembro a dezembro, está relacionada com as temperaturas elevadas, geralmente superiores a $30^{\circ} \mathrm{C}$, e com a ocorrência de chuvas escassas e irregulares na região. Bilar et al. (2018), realizando o monitoramento da cobertura vegetal através de índices biofísicos no Parque Estadual Mata da Pimenteira (PEMP), semiárido de Pernambuco, encontraram resultados semelhantes, em que no ano de 2016, começo do período mais seco da região, os resultados do índice NDVI foram menores do que 0,40 , indicando elevado estresse hídrico, ausência de folhas e grandes áreas de solo exposto. No semiárido nordestino, a variabilidade climática, em particular relacionada à seca, é sinônimo de enfrentamento de desafios para as populações rurais do interior da região e tem sido objeto de preocupação da sociedade e de setores do governo ao longo dos anos (Marengo et al., 2011).

Quando comparados os NDVIs dos períodos seco de 2020 com o período chuvoso de 2019, percebe-se que no período chuvoso, os valores de NDVI são mais elevados (mais próximos de 1), indicando maior exuberância, desenvolvimento e densidade da vegetação durante o período com maiores índices pluviométricos.
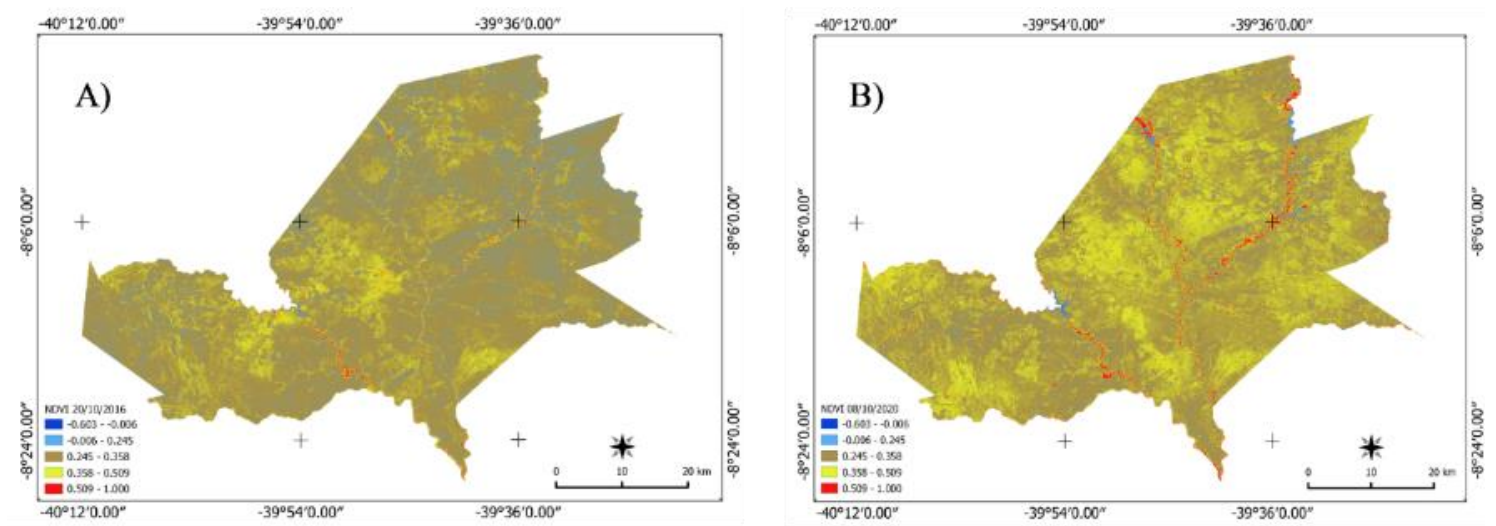

Figura 5. Comparativo dos Índices de Vegetação por Diferença Normalizada (NDVI) do município de Parnamirim - PE para as datas: 29/10/2016 (A) e 08/10/2020 (B), períodos secos (Fonte: Elaborado pelos autores).

O NDWI no período seco de 2016 apresentou valores predominantes entre -0,373 e 0,123, representados pelas cores laranja e azul claro, indicando baixos índices de solo úmido (Figura 6A). No ano de 2020, o NDWI também esteve predominantemente no intervalo de -0,373 e 0,123, entretanto, com maiores áreas com NDWI entre 0,126 e 0,645 (azul escuro), indicando maior presença de água no solo, quando comparado ao ano de 2016 (Figura 4B). Bilar et al. (2018) verificaram que NDWI com valores positivos foram detectados apenas em pontos isolados nos reservatórios e cursos d'água na região.

Quando comparados os NDWls dos períodos seco de 2020 com o período chuvoso de 2019, 
SILVA, Geovane de Andrade; FARIAS, Carolyne Wanessa Lins de Andrade (2021)

Análise espaço-temporal da vegetação no semiárido do Nordeste brasileiro utilizando parâmetros biofísicos

percebe-se que no período chuvoso, os valores de NDWI são mais elevados (com maior predominância da faixa $0,123-0,645)$, indicando maior presença de umidade no solo e menor estresse hídrico durante o período com maiores índices pluviométricos. Dentro deste contexto, evidencia-se que a vulnerabilidade ambiental do semiárido associada ao clima da região, impõe a necessidade de recuperação e de preservação da cobertura natural, podendo-se utilizar práticas indutoras de prosperidade social em harmonia com o ambiente (Lacerda et al., 2018).
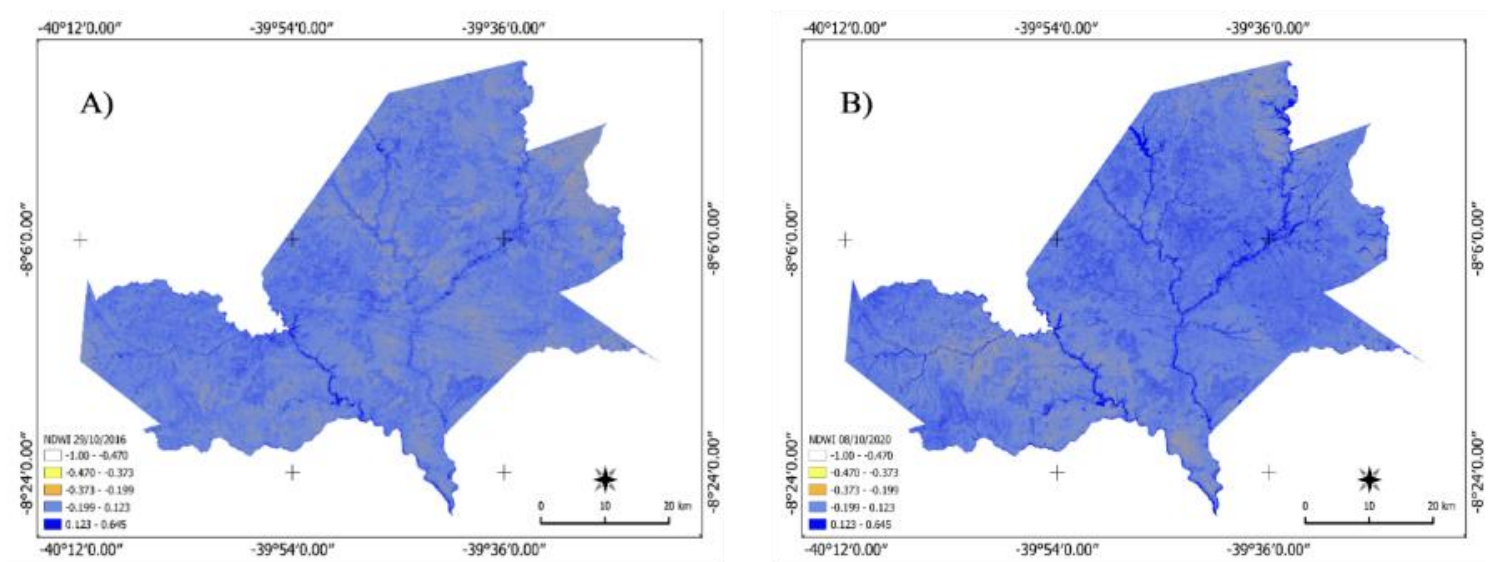

Figura 6. Comparativo dos Índices de Umidade por Diferença Normalizada (NDWI) do município de Parnamirim - PE para as datas: 29/10/2016 (A) e 08/10/2020 (B), períodos secos.

\section{Conclusões}

Os índices biofísicos NDVI e NDWI foram eficazes para a compreensão da variabilidade espaço-temporal, vigor vegetativo e presença de umidade nas áreas vegetativas da área estudada.

Os períodos secos revelaram menor exuberância da vegetação, em relação ao período chuvoso, indicando a necessidade de adoção de estratégias para convivência com eventos extremos de seca.

Áreas com menor exuberância de vegetação, podem ser adotadas como prioritárias para a adoção de ações de recuperação.

As informações geradas por este estudo são relevantes para subsidiar ações de recuperação de áreas degradadas, criação de políticas públicas, planejamento e gestão ambiental.

\section{Referências}

AZEVEDO, E.C.; MANGABEIRA, J.A.C. Mapeamento de uso das terras utilizando processamento digital de imagem de sensoriamento remoto. Comunicado Técnico, Ministério da Agricultura, Pecuária e Abastecimento, 7: 5-16, 2001.

BILAR, A.B.C.; PIMENTEL, R.M.M.; CERQUEIRA, M.A. Monitoramento da cobertura vegetal através de índices biofísicos e gestão de áreas protegidas. Geosul, 33(68): 236-259, 2018.

BRITO, P.V.S.; MORAIS, Y.C.B.; FERREIRA, H.S., SILVA, J.F.; GALVÍNCIO, J.D. Análise comparativa da umidade da vegetação de áreas de caatinga preservada, agricultura irrigada e sequeiro. Jounal of Environmental Analysis and Progress, 02(03): 493-498, 2017. 
SILVA, Geovane de Andrade; FARIAS, Carolyne Wanessa Lins de Andrade (2021).

Análise espaço-temporal da vegetação no semiárido do Nordeste brasileiro utilizando parâmetros biofísicos

FREIRE, N.C.F.; PACHECO, A.P. Mapas como expressão de poder e legitimação sobre o território: uma breve evolução histórica da cartografia como objeto de interesse de distintos grupos sociais. In: Anais do III Simpósio Brasileiro de Ciências Geodésicas e Tecnologias da Geoinformação, Recife, 2010, 1-09, 2010.

GAO, B.C. NDWI - A normalized difference water index for remote sensing of vegetation liquid water from space. Remote Sensing of Environment, 58: 257-266, 1996.

GONZAGA, E.P.; SANTOS, V.V.; NICÁCIO, R.M. Análise do comportamento do NDVI e NDWI em períodos de diferentes intensidades pluviométricas no Sertão alagoano. In: Anais do Simpósio Brasileiro de Sensoriamento Remoto, Curitiba, 2011, 1736-1743, 2011.

ITO, M.H.; FILHO, H.F.; CONTI, L.A. Uso do software livre QGIS (Quantum GIS) para ensino de geoprocessamento em nível superior. Revista cartográfica, 94: 127-148, 2017.

SILVA JÚNIOR, J.A.; MORAES, V.S.; CANDEIAS, A.L.B.; JÚNIOR, J.R.T. Análise do NDVI e NDWI e umidade local no munícipio de Água Branca - AL. In: Anais do Congresso Técnico Científico da Engenharia e da Agronomia, Maceió, 2018, 1 - 5, 2018.

LACERDA, F.F.; LOPES, G.M.B.; ALBUQUERQUE, M.M. Viveiros educadores na caatinga - mitigação aos efeitos da mudança do clima no semiárido brasileiro. Agrometeoros, 26(2): 353-361, 2018.

LIMA, L.B; CARVALHO, H.D.S. A evolução de vegetação e água como indicadores da ocorrência de desmatamento na APA Serra Branca/Raso da Catarina em Jeremoabo-BA. In: Anais do XIX Encontro Nacional de Geógrafos, João Pessoa, 2018, 1-11, 2018.

MARENGO, J.A.; ALVES, ML.; BESERRA, E. A.; LACERDA, F.F. Variabilidade e mudanças climáticas no semiárido brasileiro. Org. por Medeiros, S.S.; Gheyi, H.R.; Galvão, C.O.; Paz, V.P.S., Instituto Nacional do Semiárido (INSA), Campina Grande - PB, 383-423, 2011.

OLIVEIRA, T.H.; SILVA, J.S.; MACHADO, C.C.C.; GALVINCIO, J.D.; NÓBREGA, R.S.; PIMENTEL, R.M.M. Detecção espaço- temporal de estresse hídrico na vegetação do semiárido no nordeste do Brasil utilizando NDVI e NDWI - Estudo de caso Serra da Capivara e Serra do Congo - PI. In: Anais do VI Seminário latino Americano de Geografia Física, Coimbra, 2010.

REBOUÇAS, I.S.; DUARTE, C.R.; SILVA NETO, C.A.; MIRANDA, M.P. Aplicação do Índice de Vegetação da Diferença Normalizada (NDVI) e Água (NDWI) para análise de depósitos argilosos e arenosos no baixo curso do Rio Jaguaribe/CE. In: Anais do XIX Simpósio Brasileiro de Sensoriamento Remoto, Santos, 2019, 183-186, 2019.

ROUSE, J.W.; HAAS, R.H.; SCHELL, J.A.; DEERING, D.W. Monitoring vegetation systems in the great plains with ERTS. In: Third Earth Resources Technology Satellite Symposium, Washington, 1973, 309317, 1973.

SANTOS, S.R.Q.; CUNHA, A.P.M.A.; RIBEIRO-NETO, G.G. Avaliação de dados de precipitação para o monitoramento do padrão espaço-temporal da seca no Nordeste do Brasil. Revista Brasileira de Climatologia, 25: 80-100, 2019. 